\title{
Dietary pattern and breast cancer risk in Japanese women: the Japan Public Health Center-based Prospective Study (JPHC Study)
}

\author{
Sangah Shin ${ }^{1}$, Eiko Saito ${ }^{1,2}$, Manami Inoue ${ }^{1,2 *}$, Norie Sawada ${ }^{2}$, Junko Ishihara ${ }^{3}$, Ribeka Takachi ${ }^{4}$, \\ Akiko Nanri ${ }^{5}$, Taichi Shimazu ${ }^{2}$, Taiki Yamaji ${ }^{2}$, Motoki Iwasaki ${ }^{2}$, Shizuka Sasazuki ${ }^{2}$ and \\ Shoichiro Tsugane ${ }^{2}$ for the JPHC Study Group $\dagger$ \\ ${ }^{1}$ Graduate School of Medicine, The University of Tokyo, 7-3-1 Hongo, Bunkyo-ku, Tokyo 113-0033, Japan \\ ${ }^{2}$ Epidemiology and Prevention Group, Research Center for Cancer Prevention and Screening, National Cancer Center, \\ 5-1-1 Tsukiji, Chuo-ku, Tokyo 104-0045, Japan \\ ${ }^{3}$ Department of Nutrition Science, Sagami Women's University, 2-1-1 Bunkyo, Minami-ku, Sagamihara 252-0383, Japan \\ ${ }^{4}$ Department of Food Science and Nutrition, Faculty of Human Life and Environment, Nara Women's University, \\ Kitauoyanishi-machi, Nara 630-8506, Japan \\ ${ }^{5}$ Department of Epidemiology and Prevention, International Clinical Research Center, National Center for Global Health and \\ Medicine, 1-21-1 Toyama, Shinjuku-ku, Tokyo 162-8655, Japan
}

(Submitted 30 September 2015 - Final revision received 7 February 2016 - Accepted 8 February 2016 - First published online 21 March 2016)

\begin{abstract}
Evidence that diet is associated with breast cancer risk is inconsistent. Most of the studies have focused on risks associated with specific foods and nutrients, rather than overall diet. In this study, we aimed to evaluate the association between dietary patterns and breast cancer risk in Japanese women. A total of 49552 Japanese women were followed-up from 1995 to 1998 (5-year follow-up survey) until the end of 2012 for an average of 14.6 years. During 725534 person-years of follow-up, 718 cases of breast cancer were identified. We identified three dietary patterns (prudent, westernised and traditional Japanese). The westernised dietary pattern was associated with a $32 \%$ increase in breast cancer risk (hazard ratios (HR) 1.32; $95 \%$ CI 1.03, 1.70; $P_{\text {trend }}=0.04$ ). In particular, subjects with extreme intake of the westernised diet (quintile (Q) Q5_5th) had an $83 \%$ increase in risk of breast cancer in contrast to those in the lowest Q1 (HR 1.83; 95\% CI $1 \cdot 25,2 \cdot 68 ; P_{\text {trend }}=0 \cdot 01$ ). In analyses stratified by menopausal status, postmenopausal subjects in the highest quintile of the westernised dietary pattern had a $29 \%$ increased risk of breast cancer (HR 1.29; $95 \%$ CI 0.99, 1.76; $P_{\text {trend }}=0.04$ ). With regard to hormone receptor status, the westernised dietary pattern was associated with an increased risk of oestrogen receptor-positive/progesterone receptor-positive tumours (HR 2.49; $95 \%$ CI 1.40, $\left.4.43 ; P_{\text {trend }}<0.01\right)$. The other dietary patterns were not associated with the risk of breast cancer in Japanese women. A westernised dietary pattern is associated with an increased risk of breast cancer in Japanese women.
\end{abstract}

Key words: Breast cancer: Dietary patterns: Factor analyses: Epidemiological studies: Cohort studies

Breast cancer is a leading cause of cancer mortality worldwide and the most common form of cancer affecting women ${ }^{(1)}$. In 2012, approximately 1.7 million women were diagnosed with breast cancer, with 522000 related deaths - an increase in breast cancer incidence and related mortality by nearly $18 \%$ from $2008^{(2)}$. In Japan, the incidence of breast cancer has continuously and rapidly increased over the last three decades, and breast cancer is currently the most common cancer affecting females, as in Western countries ${ }^{(3)}$. Diet is a modifiable risk factor for breast cancer, and several single foods and nutrients have been examined in association with breast cancer risk, including vegetables, fibre and vitamins ${ }^{(4-6)}$. However, results from studies on individual foods and nutrients may be inconsistent because these cannot account for the complex interactions that occur between the various nutrients and other components of different foods ${ }^{(7,8)}$. Furthermore, dietary patterns in Asian countries differ from those in Western countries: the traditional Japanese diet, for example, is composed primarily of steamed rice, miso soup, various vegetables, fermented foods with salt and fish. Thus, many researchers have recently focused on dietary pattern analysis, a statistical method that describes the overall

Abbreviations: ER, oestrogen receptor; PR, progesterone receptor; Q, quintile.

* Corresponding author: M. Inoue, email mnminoue@m.u-tokyo.ac.jp

$\dagger$ Study group members are listed in the Appendix. 
diet. Several previous studies investigating dietary patterns in relation to breast cancer risk have shown an inverse association with the prudent/healthy dietary pattern, which usually includes high intake of vegetables, fruits, whole grains and fish ${ }^{(9-13)}$, and a positive association with the western/ unhealthy pattern, which is generally characterised by high intake of red meat, refined grains, potatoes and fat ${ }^{(14-17)}$. Given that dietary patterns are likely to vary among populations because of geographic characteristics and cultural differences in food habits, preferences and availability ${ }^{(18)}$, these reports are of limited value for the prevention and management of breast cancer in the Japanese population. Moreover, information from Japanese populations is scant: one study in Japanese women reported that the prudent dietary pattern decreased the risk of breast cancer, but this was carried out using a case-control $\operatorname{design}^{(10)}$, and no prospective study among Japanese women has yet been conducted.

In this study, using data from the Japan Public Health Centerbased Prospective Study (JPHC Study), we evaluated the relationship between dietary pattern and risk of breast cancer among Japanese women. Further, we identified associations by subtype and hormone receptor status using principal component factor analysis.

\section{Methods \\ Study population}

The JPHC Study was launched in 1990 for Cohort I and in 1993 for Cohort II. Details of the study design have been described previously ${ }^{(19)}$. This study was approved by the Institutional Review Board of the National Cancer Center of Japan and the University of Tokyo. A total of 140420 subjects were invited to participate in the baseline survey (1990-1994), of whom 71698 were women. Subjects registered at one public healthcare centre area ( $n$ 4178) were excluded because information on cancer incidence was not available. Cohort participants responded to a self-administered questionnaire at baseline from 1990 to 1994. A 5-year follow-up survey was conducted from 1995 to 1998. Compared with the original baseline survey, the follow-up provided greater detail on the frequency of food intake, and was therefore selected as baseline for the present study. After exclusion of subjects who were ineligible (non-Japanese ethnicity, late report of migration occurring before the start of the study or incorrect birth data), deceased or had moved out of a study area, 62787 women were eligible for participation. Of these, 52484 women responded to the 5-year follow-up survey (response rate $=84 \%$ ). We further excluded participants with a self-reported history of cancer occurring before the start of the follow-up ( $n$ 1861), and those with extreme total energy intake ( $\pm 3 \mathrm{SD}$ ) at the 5-year follow-up survey ( $n$ 581). Consequently, 49552 women were ultimately enrolled to assess the association between dietary pattern and breast cancer risk.

\section{Assessment of dietary pattern}

Dietary assessment was performed using a validated selfreported FFQ. The 5-year follow-up survey enquired about the consumption of 147 food and beverage items over the previous year ${ }^{(20)}$. The frequency of most food items was divided into nine categories (never, 1-3 times/month, 1-2 times/week, 3-4 times/week, 5-6 times/week, 1 time/d, 2-3 times/d, 4-6 times/d, and $\geq 7$ times/d). Slightly different categories were used for beverage intake. A standard portion size was specified for each food item, and respondents were asked to choose their usual portion size from three options (less than half, standard or $>1.5$ times). Daily food intake was calculated by multiplying daily consumption frequency by the individual's usual portion size. The validity and reproducibility of the FFQ have both been described previously ${ }^{(21-23)}$.

Details regarding the identification of dietary patterns have been described elsewhere ${ }^{(24)}$. In brief, we used 134 food and beverage items from the FFQ to derive dietary patterns. Some foods or food groups that were similar in nutritional content or culinary use were combined, making a total of forty-eight food groups. We performed principal component analysis based on log-transformed intakes of these forty-eight food groups. We determined factors by eigenvalues of $>1.75$ and a scree plot and interpretability of the derived factors. The factors were then rotated by orthogonal transformation (varimax rotation) to increase interpretability while maintaining uncorrelated factors. Dietary patterns were named according to food items that had the highest weight in each of the three factors. The factor scores for each dietary pattern were calculated for each participant by summing the intake of food items weighted by their factor loadings. Scores were energy adjusted using the residual method. The validity and reproducibility of the identified dietary patterns were determined to be acceptable ${ }^{(24)}$. Regarding reproducibility, Spearman's correlation coefficients between the two FFQ ranged from 0.55 for the prudent pattern to 0.71 for the westernised pattern in women ${ }^{(24)}$. Regarding validity, the corresponding values between dietary records and the FFQ ranged from 0.36 for the prudent pattern to 0.63 for the traditional pattern in women ${ }^{(24)}$.

\section{Ascertainment of breast cancer cases and follow-up of the cohort}

Breast cancer cases were identified through active patient notification from major local hospitals in the study area and data linkage with population-based cancer registries, with permission from the local governments responsible for the registries. Breast cancer cases were defined with reference to the Third Edition of the International Classification of Diseases for Oncology as codes C500-509. Information on oestrogen receptor (ER) and progesterone receptor (PR) status was evaluated by either immunohistochemical assay or ELISA. The cut-off points for a positive status for ER and PR were defined by clinical estimation for medical treatment or were specified by the assay method.

Subjects were enrolled to the study on the administration date of the 5-year follow-up survey, and contributed person-time from enrolment until the date of diagnosis with breast cancer, date of death, date of moving away from the study area or the end of follow-up (31 December 2012), whichever occurred first. 


\section{Statistical analysis}

We used multivariable Cox proportional hazards regression models to examine the hazard ratios (HR) and 95\% CI for breast cancer risk across the quintile categories of each dietary pattern score, taking the lowest quintile category as reference. The basic model was adjusted for age $(<50,50-54.9,55-59.9$, 60-64.9, 65-69.9, $\geq 70$ years) and public healthcare centre area, whereas the multi-variable model was further adjusted for log-transformed energy intake (continuous), BMI $(<22 \cdot 5$, $22 \cdot 5-24 \cdot 9,25-27 \cdot 4, \geq 27 \cdot 5 \mathrm{~kg} / \mathrm{m}^{2}$ ), smoking status (never, past, current), leisure-time physical activity ( $<1 \mathrm{~d} /$ month, $1-3 \mathrm{~d}$ / month, $\geq 1 \mathrm{~d} /$ week), total physical activity (metabolic equivalent task-h/d), age at menarche ( $\leq 13,14,15, \geq 16$ years, missing), parity (nulliparous, 1, 2-3, $\geq 4$ ), age at first birth (nulliparous, $<26$, $\geq 26$ years, missing), menopause status (premenopause, age at menopause $<51, \geq 51$ years) and use of exogenous female hormones (never, ever). Trend associations were assessed by assigning ordinal numbers (0-4) to quintile categories of each dietary pattern. We performed an analysis stratified by menopausal status. We focused on menopausal status obtained at the time of diagnosis (the censored date). As no previous study had direct information on menopausal status at the time of diagnosis for breast cancer, we used 51 years as a proxy cut-off for menopausal age at the 5-year follow-up survey, the time at which approximately $50 \%$ of the women had become postmenopausal ${ }^{(25)}$. Postmenopausal breast cancer was defined in those who reported being postmenopausal at the 5-year follow-up survey and/or were 51 years or older at the time of diagnosis. All other breast cancers were defined as premenopausal. For non-cases of breast cancer, when participants were 51 years or older and/or reported being postmenopausal at baseline, the years of observation were considered as postmenopausal period. When women who reported no to being postmenopausal at baseline were younger than 51 years of age at the censored date, the years of observation were considered as premenopausal period. We computed $P_{\text {interaction values using a likelihood-ratio test }}$ to compare Cox proportional hazards models with and without cross-product terms for menopausal status and each dietary pattern category in analyses stratified by menopausal status. The associations were also evaluated according to ER and PR status, as well as for combinations of them. All $P$ values presented are two-tailed and were considered to be statistically significant when $P<0 \cdot 05$. All statistical analyses were conducted using SAS version 9.3 software (SAS Institute Inc.).

\section{Results}

Three main dietary patterns were derived from 49552 Japanese women from the JPHC Study (Table 1). Patterns were named according to the food groups that had high loadings or the characteristics of the food group that composed the dietary pattern. The prudent dietary pattern was characterised by high consumption of vegetables, fruits, soya products, potatoes, seaweed, mushroom, and fish; the westernised dietary pattern was correlated with high intake of bread, meat, processed meats, dairy products, soup, coffee, soft drinks, black tea,
Table 1. Factor-loading* matrix for major dietary patterns identified by principal component analysis ( $n$ 49552)

\begin{tabular}{|c|c|c|c|c|}
\hline \multirow[b]{2}{*}{ Foods/food groups } & \multirow{2}{*}{$\frac{\text { Factor } 1}{\text { Prudent }}$} & \multirow{2}{*}{$\frac{\text { Factor } 2}{\text { Westernised }}$} & \multirow{2}{*}{$\frac{\text { Factor } 3}{\text { Traditional }}$} & \\
\hline & & & & \\
\hline Noodles & 0.55 & 0.20 & 0.14 & \\
\hline Rice & & & 0.20 & \\
\hline Bread & 0.45 & 0.34 & & \\
\hline Potatoes & 0.72 & & & \\
\hline Soya products & 0.68 & & & \\
\hline Miso soup & 0.13 & & 0.22 & \\
\hline Nuts & 0.31 & 0.23 & 0.24 & \\
\hline Green, leafy vegetables & 0.65 & & 0.18 & \\
\hline Other green vegetables & 0.65 & & 0.24 & \\
\hline Dark-yellow vegetables & 0.56 & & 0.08 & \\
\hline Tomatoes & 0.45 & 0.16 & 0.25 & \\
\hline Other vegetables & 0.71 & & 0.14 & \\
\hline Pickles & 0.46 & & 0.42 & \\
\hline Other fruits & 0.74 & & 0.22 & \\
\hline Citrus fruits & 0.63 & & $0 \cdot 20$ & \\
\hline Fruit juice & 0.17 & 0.34 & & \\
\hline Mushrooms & 0.63 & 0.15 & 0.20 & \\
\hline Seaweeds & 0.73 & & & \\
\hline Seafood other than fish & 0.37 & 0.15 & 0.54 & \\
\hline Oily fish & 0.39 & & 0.46 & \\
\hline Salmon & 0.18 & & 0.62 & \\
\hline Eel & & 0.40 & 0.22 & \\
\hline Lean fish & 0.25 & 0.22 & 0.48 & \\
\hline Salty fish & 0.24 & & 0.62 & \\
\hline Fish products & 0.36 & 0.19 & 0.29 & \\
\hline Pork & & 0.35 & 0.40 & \\
\hline Beef & & 0.46 & 0.26 & \\
\hline Chicken & & 0.31 & 0.53 & \\
\hline Liver & & 0.32 & 0.33 & \\
\hline Processed meats & 0.14 & 0.48 & 0.33 & \\
\hline Eggs & 0.24 & 0.17 & 0.32 & \\
\hline Milk & 0.18 & 0.22 & 0.19 & \\
\hline Dairy products & 0.25 & 0.37 & 0.24 & \\
\hline Soup & 0.14 & 0.57 & & \\
\hline Confectioneries & 0.48 & 0.31 & 0.19 & \\
\hline Green tea & 0.39 & & & \\
\hline Coffee & $0 \cdot 16$ & 0.47 & & \\
\hline Soft drink & & 0.38 & & \\
\hline Oolong tea & $0 \cdot 14$ & 0.46 & & \\
\hline Black tea & 0.16 & 0.50 & & \\
\hline Sauces & 0.40 & 0.46 & & \\
\hline Mayonnaise & 0.40 & 0.38 & 0.17 & \\
\hline Dressing & 0.32 & 0.53 & & \\
\hline Beer & & 0.25 & & \\
\hline Whisky & & 0.14 & & \\
\hline Wine & & $0 \cdot 21$ & & \\
\hline Eigenvalue & 9.9 & $2 \cdot 6$ & 1.8 & \\
\hline $\begin{array}{l}\text { Variance explained by each } \\
\text { factor }\end{array}$ & $20 \cdot 7$ & $5 \cdot 5$ & 3.7 & $29 \cdot 9$ \\
\hline
\end{tabular}

* Factor loading scores less than -0.14 and +0.14 are not shown.

sauces, mayonnaise and dressing; and the traditional Japanese dietary pattern was characterised by high intake of salmon, seafood other than fish, oily fish, lean fish, salty fish, chicken and pickles. These three dietary patterns account for $29.9 \%$ of the variability in the standardised dietary intake, at 20.7, 5.5 and $3.7 \%$ for the prudent, westernised and traditional Japanese diets, respectively.

Subject characteristics by quintile category of the three dietary patterns are presented in Table 2. Women in the highest quintile of the prudent dietary pattern score were more likely to be older, 
Table 2. Subject characteristics according to quintiles $(Q)$ of dietary pattern score at the 5-year follow-up study (Mean values and standard deviations)

\begin{tabular}{|c|c|c|c|c|c|c|c|c|c|c|c|}
\hline & \multicolumn{2}{|c|}{ Q1 } & \multicolumn{2}{|c|}{ Q2 } & \multicolumn{2}{|c|}{ Q3 } & \multicolumn{2}{|c|}{ Q4 } & \multicolumn{2}{|c|}{ Q5 } & \multirow[b]{2}{*}{$P_{\text {trend }}{ }^{*}$} \\
\hline & Mean & SD & Mean & SD & Mean & SD & Mean & SD & Mean & SD & \\
\hline \multicolumn{12}{|l|}{ Prudent } \\
\hline Age at baseline (years) & $56 \cdot 9$ & 8.1 & $56 \cdot 2$ & 7.9 & $57 \cdot 0$ & 7.9 & 57.6 & $7 \cdot 8$ & $59 \cdot 0$ & 7.9 & $<0.01$ \\
\hline $\mathrm{BMI}$ at baseline $\left(\mathrm{kg} / \mathrm{m}^{2}\right)$ & $23 \cdot 6$ & $3 \cdot 3$ & 23.5 & $3 \cdot 2$ & 23.5 & 3.2 & 23.4 & 3.1 & $23 \cdot 6$ & $3 \cdot 2$ & 0.62 \\
\hline Height $(\mathrm{cm})$ & 151.6 & $5 \cdot 8$ & $152 \cdot 0$ & 5.6 & 151.9 & 5.5 & $151 \cdot 7$ & 5.5 & 151.4 & 5.4 & 0.02 \\
\hline Total physical activity (MET-h/d) & 29.9 & 5.9 & $30 \cdot 2$ & $6 \cdot 0$ & $30 \cdot 1$ & 5.9 & $30 \cdot 0$ & 5.8 & $30 \cdot 1$ & 5.7 & 0.01 \\
\hline Total energy intake (kJ/d) & $8253 \cdot 7$ & $3406 \cdot 6$ & $8488 \cdot 4$ & 2709.5 & 7986.4 & $2328 \cdot 3$ & $7468 \cdot 0$ & $2075 \cdot 2$ & 6585.6 & $1985 \cdot 3$ & \\
\hline Total energy intake $(\mathrm{kcal} / \mathrm{d})$ & $1972 \cdot 7$ & $814 \cdot 2$ & $2028 \cdot 8$ & 647.6 & $1908 \cdot 8$ & 556.5 & 1784.9 & 496.0 & 1574.0 & 474.5 & $<0.01$ \\
\hline Smoking status (past or current) (\%) & \multicolumn{2}{|c|}{$12 \cdot 1$} & \multicolumn{2}{|c|}{$7 \cdot 6$} & \multicolumn{2}{|c|}{$5 \cdot 7$} & \multirow{2}{*}{\multicolumn{2}{|c|}{$\begin{array}{r}4.1 \\
13.5\end{array}$}} & \multicolumn{2}{|c|}{4.0} & $<0.01$ \\
\hline Alcohol drinking status (ever drinkers) (\%) & \multicolumn{2}{|c|}{30.5} & \multicolumn{2}{|c|}{$25 \cdot 6$} & \multicolumn{2}{|c|}{19.5} & & & \multicolumn{2}{|c|}{8.7} & $<0.01$ \\
\hline Age at menarche (years) & 14.9 & $2 \cdot 0$ & $14 \cdot 7$ & 1.9 & $14 \cdot 6$ & 1.8 & $14 \cdot 7$ & 1.9 & $14 \cdot 8$ & 1.9 & $<0.01$ \\
\hline Age at first birth (years) & 24.7 & 3.6 & 24.9 & 3.4 & 24.9 & 3.3 & $25 \cdot 0$ & 3.4 & 24.9 & 3.4 & $<0.01$ \\
\hline No. of children $(n)$ & $2 \cdot 8$ & 1.6 & $2 \cdot 7$ & 1.4 & $2 \cdot 7$ & 1.4 & $2 \cdot 7$ & 1.4 & $2 \cdot 8$ & 1.6 & 0.09 \\
\hline Age at menopause (years) & $48 \cdot 1$ & 4.9 & $48 \cdot 2$ & 4.9 & $48 \cdot 4$ & 4.7 & 48.4 & 4.7 & 48.5 & 4.8 & $<0.01$ \\
\hline Use of exogenous female hormones (ever) (\%) & \multicolumn{2}{|c|}{$27 \cdot 5$} & \multicolumn{2}{|c|}{26.5} & \multicolumn{2}{|c|}{$25 \cdot 7$} & \multicolumn{2}{|c|}{$25 \cdot 5$} & & & 0.09 \\
\hline Westernised & & & & & & & & & & & \\
\hline Age at baseline (years) & $61 \cdot 0$ & 7.3 & 58.6 & 7.8 & $57 \cdot 1$ & 7.9 & 55.9 & 7.8 & $54 \cdot 1$ & $7 \cdot 4$ & $<0.01$ \\
\hline BMI at baseline $\left(\mathrm{kg} / \mathrm{m}^{2}\right)$ & 23.5 & 3.2 & 23.5 & 3.2 & 23.5 & $3 \cdot 2$ & 23.5 & 3.2 & 23.5 & 3.2 & 0.22 \\
\hline Height $(\mathrm{cm})$ & $150 \cdot 6$ & 5.7 & $151 \cdot 2$ & 5.5 & $151 \cdot 8$ & 5.5 & $152 \cdot 2$ & 5.5 & $152 \cdot 7$ & 5.5 & $<0.01$ \\
\hline Total physical activity (MET-h/d) & 29.9 & 5.7 & $30 \cdot 2$ & 5.9 & $30 \cdot 2$ & 5.9 & $30 \cdot 2$ & 5.8 & $29 \cdot 9$ & 5.8 & 0.96 \\
\hline Total energy intake $(\mathrm{kJ} / \mathrm{d})$ & 7635.8 & $2725 \cdot 8$ & $7703 \cdot 1$ & $2608 \cdot 7$ & 7823.6 & $2630 \cdot 0$ & $7937 \cdot 0$ & 2648.4 & $7682 \cdot 2$ & 2583.6 & \\
\hline Total energy intake (kcal/d) & $1825 \cdot 0$ & 651.5 & $1841 \cdot 1$ & 623.5 & $1869 \cdot 9$ & 628.6 & $1897 \cdot 0$ & 633.0 & $1836 \cdot 1$ & 617.5 & 0.22 \\
\hline Smoking status (past or current) (\%) & & & & & & & & & & & $<0.01$ \\
\hline Alcohol drinking status (ever drinkers) (\%) & & & & & & & & & & & $<0.01$ \\
\hline Age at menarche (years) & $15 \cdot 1$ & 1.9 & 14.9 & 1.9 & 14.7 & 1.9 & 14.5 & 1.9 & 14.4 & 1.8 & $<0.01$ \\
\hline Age at first birth (years) & 24.5 & $3 \cdot 3$ & $24 \cdot 7$ & $3 \cdot 3$ & 24.9 & 3.4 & $25 \cdot 0$ & 3.4 & $25 \cdot 2$ & 3.5 & $<0.01$ \\
\hline No. of children $(n)$ & 2.9 & 1.6 & $2 \cdot 8$ & 1.5 & $2 \cdot 7$ & 1.4 & $2 \cdot 7$ & 1.5 & $2 \cdot 7$ & 1.5 & $<0.01$ \\
\hline Age at menopause (years) & 48.5 & 4.6 & 48.4 & 4.7 & 48.3 & $4 \cdot 8$ & $48 \cdot 2$ & 4.8 & 48.0 & 4.9 & $<0.01$ \\
\hline Use of exogenous female hormones (ever) (\%) & & & & & & & & & & & $<0.01$ \\
\hline Traditional & & & & & & & & & & & \\
\hline Age at baseline (years) & 58.6 & 8.4 & $57 \cdot 0$ & $8 \cdot 1$ & $56 \cdot 4$ & 7.9 & $56 \cdot 6$ & 7.7 & $58 \cdot 0$ & 7.7 & $<0.01$ \\
\hline BMl at baseline $\left(\mathrm{kg} / \mathrm{m}^{2}\right)$ & 23.8 & $3 \cdot 4$ & $23 \cdot 4$ & $3 \cdot 2$ & $23 \cdot 4$ & 3.2 & $23 \cdot 4$ & 3.1 & $23 \cdot 4$ & 3.1 & $<0.01$ \\
\hline Height $(\mathrm{cm})$ & $151 \cdot 1$ & 5.6 & $152 \cdot 1$ & 5.6 & $152 \cdot 3$ & 5.4 & 151.9 & 5.6 & $151 \cdot 2$ & 5.6 & 0.18 \\
\hline Total physical activity (MET-h/d) & 30.0 & 5.9 & $30 \cdot 2$ & 5.8 & $30 \cdot 2$ & 5.8 & $30 \cdot 1$ & 5.8 & 29.9 & 5.9 & 0.42 \\
\hline Total energy intake $(\mathrm{kJ} / \mathrm{d})$ & 7468.4 & $2938 \cdot 4$ & $8113 \cdot 6$ & $2844 \cdot 2$ & 8184.7 & $2597 \cdot 8$ & $7870 \cdot 1$ & 2345.9 & 7141.6 & $2268 \cdot 1$ & \\
\hline Total energy intake $(\mathrm{kcal} / \mathrm{d})$ & $1785 \cdot 8$ & $702 \cdot 3$ & $1939 \cdot 2$ & 679.8 & $1956 \cdot 2$ & 620.9 & $1881 \cdot 0$ & $560 \cdot 7$ & $1706 \cdot 9$ & $542 \cdot 1$ & $<0.01$ \\
\hline Smoking status (past or current) (\%) & & & & & & & & & & & 0.85 \\
\hline Alcohol drinking status (ever drinkers) (\%) & & & & & & & & & & & $<0.01$ \\
\hline Age at menarche (years) & $15 \cdot 3$ & $2 \cdot 1$ & $14 \cdot 6$ & 1.9 & 14.4 & 1.8 & 14.5 & 1.7 & $14 \cdot 8$ & 1.8 & $<0.01$ \\
\hline Age at first birth (years) & 24.8 & 3.8 & $25 \cdot 0$ & 3.5 & $25 \cdot 0$ & 3.4 & $24 \cdot 8$ & 3.3 & 24.7 & 3.2 & 0.03 \\
\hline No. of children $(n)$ & $3 \cdot 2$ & 1.9 & 2.8 & 1.6 & 2.6 & 1.3 & 2.5 & 1.3 & $2 \cdot 6$ & 1.2 & $<0.01$ \\
\hline Age at menopause (years) & 48.4 & 4.8 & $48 \cdot 2$ & $5 \cdot 0$ & $48 \cdot 4$ & $4 \cdot 8$ & $48 \cdot 2$ & 4.8 & 48.4 & 4.5 & 0.85 \\
\hline Use of exogenous female hormones (ever) (\%) & & & & & & & & & & & 0.08 \\
\hline
\end{tabular}

MET, metabolic equivalent task.

${ }^{*} \chi^{2}$ Test for ordinal qualitative variables and linear regression for continuous variables. 
shorter, more active, have low total energy intake, low tobacco use, low alcohol use, earlier menarche, later first delivery and later menopause compared with women in the lowest quintile of the prudent dietary pattern. Subjects with a higher score for the westernised dietary pattern were more likely to be younger, taller, have higher use of tobacco, higher use of alcohol, earlier menarche, later first delivery, less parity, earlier menopause and use of exogenous female hormones. Subjects with a higher score for the traditional Japanese dietary pattern tended to be younger, have low BMI, low total energy intake, high alcohol consumption, earlier menarche, earlier first delivery and less parity.

During 725534 person-years of follow-up (average follow-up: 14.6 years) for 49552 women, a total of 718 cases of breast cancer were newly diagnosed and included in the analyses. Information on ER and PR status was available for 356 cases (50\% of total breast cancer), of which 155 were oestrogen receptor-positive $(\mathrm{ER}+) /$ progesterone receptor-positive $(\mathrm{PR}+)$, fifty-eight were $\mathrm{ER}+$ /progesterone receptor-negative (ER-), eighty-five were oestrogen receptor-negative (ER-)/PR- and eleven were ER-/PR+ (310 cases had known ER/PR status). HR of overall breast cancer according to quintile category of each dietary pattern score are shown in Table 3 . The westernised dietary pattern was associated with an overall increase in breast cancer risk (HR 1.32; $95 \% \mathrm{CI}$ $\left.1.03,1.70 ; P_{\text {trend }}=0.04\right)$. We conducted additional analyses to identify the association between extreme intake of a westernised diet and breast cancer risk among women in the highest quintile category (Q5) of the westernised dietary pattern. Q5 of the westernised dietary pattern was further divided into additional extreme quintile categories labelled Q5_1st, Q5_2nd, Q5_3rd, Q5_4th and Q5_5th. Women categorised in Q5_5th of the westernised dietary pattern were thus in the top $4 \%$ of total subjects. The results showed that they had a $63 \%$ increase in the risk of breast cancer (HR 1.83; 95\% CI 1.25, 2.68; $\left.P_{\text {trend }}=0.01\right)$ compared with those in the original lowest Q1 (Tables 4)

In analyses stratified by menopausal status, although the positive association between the westernised dietary pattern and breast cancer risk was not significant in the full model adjusted for covariates, postmenopausal women in the highest quintile of the westernised dietary pattern had a $29 \%$ increase in risk of breast cancer $\left(95 \%\right.$ CI $\left.0.99,1.76 ; P_{\text {trend }}=0.04\right)$ (Table 5). In subanalyses that considered hormone receptor status (ER, PR), the association between the westernised dietary pattern and breast cancer risk was statistically significant only for ER+/PR+ tumours (for Q5 $v$. Q1, multivariable HR 2.49; $95 \%$ CI 1.40, 4.43; $P_{\text {trend }}<0 \cdot 01$ ) (Table 6).

No clear association was found between breast cancer risk and the prudent and traditional Japanese dietary patterns in Japanese women.

\section{Discussion}

In this study, we identified three dietary patterns in a large sample of Japanese women, which we labelled prudent, westernised and traditional dietary patterns. We found that the westernised dietary pattern was associated with an increased risk of breast cancer. This increased risk was more pronounced in women with extreme intake of a western diet
(Q5_5th category of the westernised dietary pattern), postmenopausal women and for ER+/PR+ tumours.

Results from previous studies on the association between dietary pattern and breast cancer risk have been inconsistent. Most previous prospective analyses were conducted in Western populations $^{(8,9,11,12,17,26-29)}$, and little prospective data from Asian populations with a western dietary pattern have been reported. In agreement with our findings, a previous prospective cohort study of the association between dietary pattern and breast cancer risk in France found that a western dietary pattern was positively associated with breast cancer risk $(\mathrm{HR}=1 \cdot 20)$, especially in women with $\mathrm{ER}+/ \mathrm{PR}+$ tumours $^{(30)}$. Only one Asian prospective cohort study reported a trend for lower breast cancer risk in those with higher intake of a vegetable-fruit-soya (prudent) dietary pattern, with particularly stronger effects among postmenopausal women ${ }^{(31)}$.

In the present study, the westernised dietary pattern was positively associated with breast cancer risk. Identifying the specific components (nutrients or foods) of the westernised dietary pattern that contribute to this positive association with breast cancer risk is difficult. The westernised dietary pattern in our study was characterised by high intakes of meats, processed meats, dairy products, several beverages and sauces, and alcohol, but a low intake of vegetables and fruits. A refined grainmeat-pickles pattern in Chinese women ${ }^{(32)}$ and a fatty dietary pattern in Japanese women ${ }^{(10)}$ were positively associated with breast cancer risk. A recent meta-analysis of studies concluded that the risk of breast cancer for the highest $v$. lowest categories increased by $10 \%$ for red meat and $8 \%$ for processed meat ${ }^{(33)}$. It has been hypothesised that diets with a high intake of meat and processed meat promote carcinogenesis via certain carcinogenic compounds such as heterocyclic amines (HCA) and polycyclic aromatic hydrocarbons (PAH), which are by-products of cooking meat at high temperatures ${ }^{(34,35)}$. Evidence for positive associations between HCA and PAH intake and overall breast cancer risk has been identified in human studies ${ }^{(36,37)}$

In addition, a World Cancer Research Fund/American Institute for Cancer Research report ${ }^{(38)}$ states that alcohol consumption is a risk factor for breast cancer, and most epidemiological studies have consistently identified an association between breast cancer risk and alcohol intake ${ }^{(39,40)}$. Several biological mechanisms for this association have been proposed, including an increase in circulating hormone levels, direct carcinogenic effects of alcohol metabolites such as acetaldehyde and an antagonistic effect on folate absorption and metabolism ${ }^{(41,42)}$. Furthermore, dietary behaviours such as frequent consumption of sweet soda, coffee and tea with added sugar and sauces with high fat and sugar content increase blood glucose levels. Hyperinsulinemia may be a risk factor for breast cancer as insulin is mitogenic, and thereby encourages cellular proliferation and promotes tumour growth; excess insulin is also indirectly related to increased levels of free oestrogen via inhibition of the production of sex-hormonebinding globulin ${ }^{(43)}$.

Considered broadly, these various findings may suggest that one reason for the positive association between the westernised dietary pattern and risk of breast cancer is the complex or synergistic effects achieved by combining food/food groups on breast cancer. In addition, the combined effects of dietary 


\section{Nes British Journal of Nutrition}

Table 3. Breast cancer risk according to quintiles $(\mathrm{Q})$ of dietary pattern score (Hazard ratios (HR) and $95 \%$ confidence intervals)

\begin{tabular}{|c|c|c|c|c|c|c|c|c|c|c|}
\hline \multirow[b]{3}{*}{ Dietary patterns } & \multicolumn{10}{|c|}{ Quintiles, all ( $n 49552$ breast cancer cases $=718$ ) } \\
\hline & \multirow{2}{*}{$\begin{array}{l}\mathrm{Q} 1 \\
\mathrm{HR}\end{array}$} & \multicolumn{2}{|c|}{ Q2 } & \multicolumn{2}{|c|}{ Q3 } & \multicolumn{2}{|c|}{ Q4 } & \multicolumn{2}{|c|}{ Q5 } & \multirow[b]{2}{*}{$P_{\text {trend }}{ }^{*}$} \\
\hline & & $\mathrm{HR}$ & $95 \% \mathrm{Cl}$ & $\mathrm{HR}$ & $95 \% \mathrm{Cl}$ & $\mathrm{HR}$ & $95 \% \mathrm{Cl}$ & $\mathrm{HR}$ & $95 \% \mathrm{Cl}$ & \\
\hline \multicolumn{11}{|l|}{ Prudent } \\
\hline No. of cases & 143 & \multirow{2}{*}{\multicolumn{2}{|c|}{$\begin{array}{c}131 \\
146261\end{array}$}} & \multirow{2}{*}{\multicolumn{2}{|c|}{$\begin{array}{c}159 \\
145767\end{array}$}} & \multirow{2}{*}{\multicolumn{2}{|c|}{$\begin{array}{c}146 \\
146298\end{array}$}} & \multirow{2}{*}{\multicolumn{2}{|c|}{$\begin{array}{c}139 \\
143019\end{array}$}} & \\
\hline Total person-years & 144188 & & & & & & & & & \\
\hline Age and area adjusted & 1.00 (Ref.) & 0.90 & $0.71,1.14$ & $1 \cdot 10$ & $0.88,1.38$ & 1.01 & $0.80,1.28$ & 1.01 & $0.80,1.27$ & 0.62 \\
\hline Multivariable adjusted $\dagger$ & 1.00 (Ref.) & 0.88 & $0.69,1.11$ & 1.07 & $0.85,1.35$ & 0.97 & $0.77,1.23$ & 0.96 & $0.75,1.23$ & 0.93 \\
\hline Westernised & & \multirow{3}{*}{\multicolumn{2}{|c|}{$\begin{array}{c}138 \\
147353\end{array}$}} & & & & & \multirow{3}{*}{\multicolumn{2}{|c|}{$\begin{array}{c}166 \\
140667\end{array}$}} & \\
\hline No. of cases & 125 & & & \multirow{2}{*}{\multicolumn{2}{|c|}{$\begin{array}{c}147 \\
146200\end{array}$}} & \multirow{2}{*}{\multicolumn{2}{|c|}{$\begin{array}{c}142 \\
144550\end{array}$}} & & & \\
\hline Total person-year & 146764 & & & & & & & & & \\
\hline Age and area adjusted & 1.00 (Ref.) & 1.09 & $0.85,1.38$ & $1 \cdot 16$ & $0.91,1.48$ & $1 \cdot 14$ & $0.89,1.46$ & 1.37 & $1.07,1.75$ & 0.02 \\
\hline Multivariable adjusted & 1.00 (Ref.) & 1.07 & $0.84,1.37$ & $1 \cdot 14$ & $0.89,1.46$ & $1 \cdot 10$ & $0.86,1.42$ & 1.32 & $1.03,1.70$ & 0.04 \\
\hline \multicolumn{11}{|l|}{ Traditional } \\
\hline No. of cases & 123 & \multirow{2}{*}{\multicolumn{2}{|c|}{$\begin{array}{c}151 \\
142114\end{array}$}} & \multirow{2}{*}{\multicolumn{2}{|c|}{$\begin{array}{c}161 \\
145143\end{array}$}} & \multirow{2}{*}{\multicolumn{2}{|c|}{$\begin{array}{c}140 \\
148408\end{array}$}} & \multirow{2}{*}{\multicolumn{2}{|c|}{$\begin{array}{c}143 \\
149854\end{array}$}} & \\
\hline Total person-years & 140015 & & & & & & & & & \\
\hline Age and area adjusted & 1.00 (Ref.) & $1 \cdot 18$ & $0.93,1.50$ & 1.21 & $0.96,1.54$ & 1.02 & $0.80,1.31$ & 1.04 & $0.81,1.33$ & 0.73 \\
\hline Multivariable adjusted & 1.00 (Ref.) & 1.15 & $0.91,1.47$ & 1.18 & $0.93,1.50$ & 1.00 & $0.78,1.28$ & 1.03 & $0.80,1.32$ & 0.69 \\
\hline
\end{tabular}

Ref., referent values.

* Based on a Cox proportional hazards model, with ordinal numbers $0-4$ assigned to the quintile categories of each dietary pattern.

† Multivariable adjusted: multivariable Cox proportional hazards model were adjusted for age ( $<50,50-54 \cdot 9,55-59 \cdot 9,60-64 \cdot 9,65-69 \cdot 9, \geq 70$ years), public healthcare centre area (ten), log-transformed energy intake (continuous), BMI $\left(<22.5,22 \cdot 5-24 \cdot 9,25-27 \cdot 4, \geq 27.5 \mathrm{~kg} / \mathrm{m}^{2}\right)$, smoking status (never, past, current), leisure-time physical activity $(<1 \mathrm{~d} / \mathrm{month}, 1-3 \mathrm{~d} / \mathrm{month}, \geq 1 \mathrm{~d} / \mathrm{week})$, total physical activity $(<30, \geq 30 \mathrm{metabolic}$ equivalent task-h/d, missing), age at monarche $(\leq 13,14,15, \geq 16$ years,

Table 4. Breast cancer risk according to quintiles (Q) among the highest quintile group (Q5) ( $n$ 9910, breast cancer cases $=166)$ (Hazard ratios (HR) and $95 \%$ confidence intervals)

\begin{tabular}{|c|c|c|c|c|c|c|c|c|c|c|c|c|}
\hline \multirow[b]{2}{*}{ Westernised dietary pattern } & \multirow{2}{*}{$\frac{\mathrm{Q} 1 \text { (total) }}{\mathrm{HR}}$} & \multicolumn{2}{|c|}{ Q5_1st } & \multicolumn{2}{|c|}{ Q5_2nd } & \multicolumn{2}{|c|}{ Q5_3rd } & \multicolumn{2}{|c|}{ Q5_4th } & \multicolumn{2}{|c|}{ Q5_5th } & \multirow[b]{2}{*}{$P_{\text {trend }}{ }^{*}$} \\
\hline & & $\mathrm{HR}$ & $95 \% \mathrm{Cl}$ & $\mathrm{HR}$ & $95 \% \mathrm{Cl}$ & $\mathrm{HR}$ & $95 \% \mathrm{Cl}$ & $\mathrm{HR}$ & $95 \% \mathrm{Cl}$ & $\mathrm{HR}$ & $95 \% \mathrm{Cl}$ & \\
\hline No. of cases & 125 & \multicolumn{2}{|c|}{27} & \multicolumn{2}{|c|}{33} & \multicolumn{2}{|c|}{31} & \multirow{2}{*}{\multicolumn{2}{|c|}{$\begin{array}{c}29 \\
27827\end{array}$}} & \multicolumn{2}{|c|}{46} & \\
\hline Total person-years & 146764 & & 344 & & 589 & & 279 & & & & 628 & \\
\hline Age and area adjusted & 1.00 (Ref.) & 1.05 & $0.68,1.61$ & 1.26 & $0.84,1.88$ & $1 \cdot 19$ & $0.79,1.80$ & $1 \cdot 13$ & $0.74,1.74$ & 1.80 & $1 \cdot 24,2 \cdot 61$ & 0.01 \\
\hline Multivariable adjusted $\dagger$ & 1.00 (Ref.) & 1.03 & $0.67,1.60$ & 1.25 & $0.84,1.88$ & $1 \cdot 18$ & $0.78,1.80$ & $1 \cdot 13$ & $0.73,1.74$ & 1.83 & $1 \cdot 25,2.68$ & 0.01 \\
\hline
\end{tabular}

* Based on a Cox proportional hazards model, with ordinal numbers $0-4$ assigned to the quintile categories of each dietary pattern.

† Multivariable adjusted: multivariable Cox proportional hazards model was adjusted for age (<50, 50-54.9, 55-59.9, 60-64.9, 65-69.9, $\geq 70$ years), public health centre area (ten), log-transformed energy intake (continuous), BMI $\left(<22.5,22.5-24 \cdot 9,25-27 \cdot 4, \geq 27.5 \mathrm{~kg} / \mathrm{m}^{2}\right)$, smoking status (never, past, current), leisure-time physical activity $(<1 \mathrm{~d} / \mathrm{month}, 1-3 \mathrm{~d} / \mathrm{month}, \geq 1 \mathrm{~d} / \mathrm{week})$, total physical activity $(<30, \geq 30 \mathrm{metabolic}$ equivalent task-h/d, missing), age a menarche ( $\leq 13,14,15, \geq 16$ years, missing), parity (nulliparous, $1,2-3, \geq 4$ ), age at first birth (nulliparous, $<26, \geq 26$ years, missing), menopause status (premenopause, age at menopause $<51, \geq 51$ years) and use of exogenous female 


\section{Nesitish Journal of Nutrition}

Table 5. Breast cancer risk according to quintile $(\mathrm{Q})$ of dietary pattern score with stratification by menopausal status ${ }^{*}$ (Hazard ratios (HR) and $95 \%$ confidence intervals)

\begin{tabular}{|c|c|c|c|c|c|c|c|c|c|c|}
\hline \multirow[b]{3}{*}{ Dietary patterns } & \multicolumn{9}{|c|}{ Quintiles } & \multirow[b]{3}{*}{$P_{\text {trend }} \dagger$} \\
\hline & \multirow{2}{*}{$\begin{array}{l}\text { Q1 } \\
\mathrm{HR} \\
\end{array}$} & \multicolumn{2}{|r|}{ Q2 } & \multicolumn{2}{|c|}{ Q3 } & \multicolumn{2}{|c|}{ Q4 } & \multicolumn{2}{|c|}{ Q5 } & \\
\hline & & $\mathrm{HR}$ & $95 \% \mathrm{Cl}$ & $\mathrm{HR}$ & $95 \% \mathrm{Cl}$ & $\mathrm{HR}$ & $95 \% \mathrm{Cl}$ & $\mathrm{HR}$ & $95 \% \mathrm{Cl}$ & \\
\hline \multicolumn{11}{|c|}{ Premenopausal $(n 10714$; breast cancer cases $=185)$} \\
\hline \multicolumn{11}{|l|}{ Prudent } \\
\hline No. of cases & 37 & \multirow{2}{*}{\multicolumn{2}{|c|}{$\begin{array}{c}29 \\
32346\end{array}$}} & \multirow{2}{*}{\multicolumn{2}{|c|}{$\begin{array}{c}41 \\
31856\end{array}$}} & & 6 & \multicolumn{2}{|c|}{$\begin{array}{c}32 \\
32308\end{array}$} & \\
\hline Total person-years & 31894 & & & & & & 995 & & 308 & \\
\hline Age and area adjusted & 1.00 (Ref.) & 0.77 & $0.48,1.26$ & $1 \cdot 11$ & $0.71,1.73$ & 1.24 & $0.80,1.91$ & 0.85 & $0.53,1.37$ & 0.76 \\
\hline Multivariable adjusted $\ddagger$ & 1.00 (Ref.) & 0.79 & $0.48,1.29$ & $1 \cdot 10$ & $0.70,1.73$ & 1.21 & $0.78,1.89$ & 0.83 & $0.51,1.36$ & 0.87 \\
\hline \multicolumn{11}{|l|}{ Westernised } \\
\hline No. of cases & 43 & \multirow{2}{*}{\multicolumn{2}{|c|}{$\begin{array}{c}38 \\
32625\end{array}$}} & \multirow{2}{*}{\multicolumn{2}{|c|}{$\begin{array}{c}30 \\
31993\end{array}$}} & \multirow{2}{*}{\multicolumn{2}{|c|}{$\begin{array}{c}29 \\
31570\end{array}$}} & \multirow{2}{*}{\multicolumn{2}{|c|}{$\begin{array}{c}45 \\
30478\end{array}$}} & \\
\hline Total person-years & 33732 & & & & & & & & & \\
\hline Age and area adjusted & 1.00 (Ref.) & 0.94 & $0.61,1.46$ & 0.77 & $0.48,1.23$ & 0.76 & $0.47,1.24$ & 1.24 & $0.80,1.92$ & 0.61 \\
\hline Multivariable adjusted & 1.00 (Ref.) & 0.96 & $0.62,1.49$ & 0.78 & $0.49,1.25$ & 0.77 & $0.48,1.25$ & 1.26 & $0.81,1.96$ & 0.59 \\
\hline \multicolumn{11}{|l|}{ Traditional } \\
\hline No. of cases & 31 & \multirow{2}{*}{\multicolumn{2}{|c|}{$\begin{array}{c}34 \\
31380\end{array}$}} & \multirow{2}{*}{\multicolumn{2}{|c|}{$\begin{array}{c}43 \\
31928\end{array}$}} & \multirow{2}{*}{\multicolumn{2}{|c|}{$\begin{array}{c}36 \\
32555\end{array}$}} & \multirow{2}{*}{\multicolumn{2}{|c|}{$\begin{array}{c}41 \\
33467\end{array}$}} & \\
\hline Total person-years & 31070 & & & & & & & & & \\
\hline Age and area adjusted & 1.00 (Ref.) & 1.09 & $0.67,1.77$ & 1.35 & $0.85,2.15$ & 1.11 & $0.68,1.80$ & 1.20 & $0.74,1.94$ & 0.51 \\
\hline Multivariable adjusted & 1.00 (Ref.) & $1 \cdot 12$ & $0.69,1.83$ & 1.39 & $0.87,2.23$ & 1.12 & $0.69,1.84$ & 1.22 & $0.75,1.98$ & 0.50 \\
\hline \multicolumn{11}{|c|}{ Postmenopausal ( $n$ 38 838; breast cancer cases $=533$ ) } \\
\hline \multicolumn{11}{|l|}{ Prudent } \\
\hline No. of cases & 109 & \multirow{2}{*}{\multicolumn{2}{|c|}{$\begin{array}{c}93 \\
114097\end{array}$}} & & & & 03 & & 12 & \\
\hline Total person-years & 112096 & & & & 927 & & 162 & & 853 & \\
\hline Age and area adjusted & 1.00 (Ref.) & 0.84 & $0.63,1.10$ & 1.05 & $0.81,1.36$ & 0.93 & $0.71,1.22$ & 1.06 & $0.81,1.38$ & 0.47 \\
\hline Multivariable adjusted & 1.00 (Ref.) & 0.81 & $0.61,1.07$ & 1.01 & $0.77,1.32$ & 0.89 & $0.68,1 \cdot 18$ & 1.01 & $0.77,1.34$ & 0.70 \\
\hline Westernised & & & & & & & & & & \\
\hline No. of cases & 90 & & 103 & & 06 & & 17 & & 17 & \\
\hline Total person-years & 114178 & & 114546 & & 822 & & 689 & & 899 & \\
\hline Age and area adjusted & 1.00 (Ref.) & $1 \cdot 14$ & $0.86,1.51$ & 1.18 & $0.89,1.57$ & 1.32 & $1.00,1.75$ & 1.37 & $1.03,1.82$ & 0.02 \\
\hline Multivariable adjusted & 1.00 (Ref.) & $1 \cdot 13$ & $0.85,1.50$ & 1.15 & $0.86,1.53$ & 1.28 & $0.97,1.70$ & 1.29 & $0.99,1.76$ & 0.04 \\
\hline Traditional & & & & & & & & & & \\
\hline No. of cases & 95 & & 115 & & 18 & & 03 & & 02 & \\
\hline Total person-years & 108924 & & 110822 & & 993 & & 820 & & 576 & \\
\hline Age and area adjusted & 1.00 (Ref.) & $1 \cdot 16$ & $0.88,1.52$ & $1 \cdot 15$ & $0.87,1.51$ & 0.96 & $0.72,1.28$ & 0.94 & $0.71,1.25$ & 0.31 \\
\hline Multivariable adjusted & 1.00 (Ref.) & 1.13 & $0.86,1.48$ & 1.09 & $0.83,1.44$ & 0.92 & $0.69,1.23$ & 0.92 & $0.69,1.23$ & 0.24 \\
\hline
\end{tabular}




\section{British Journal of Nutrition}

Table 6. Breast cancer risk according to quintiles $(\mathrm{Q})$ of dietary pattern score by hormone receptor status (Hazard ratios (HR) and $95 \%$ confidence intervals)

\begin{tabular}{|c|c|c|c|c|c|c|c|c|c|c|}
\hline & \multicolumn{9}{|c|}{ Quintiles } & \multirow[b]{3}{*}{$P_{\text {trend }}{ }^{*}$} \\
\hline & \multirow{2}{*}{$\frac{\mathrm{Q} 1}{\mathrm{HR}}$} & \multicolumn{2}{|c|}{ Q2 } & \multicolumn{2}{|c|}{ Q3 } & \multicolumn{2}{|c|}{ Q4 } & \multicolumn{2}{|c|}{ Q5 } & \\
\hline & & $\mathrm{HR}$ & $95 \% \mathrm{Cl}$ & $\mathrm{HR}$ & $95 \% \mathrm{Cl}$ & $\mathrm{HR}$ & $95 \% \mathrm{Cl}$ & $\mathrm{HR}$ & $95 \% \mathrm{Cl}$ & \\
\hline \multicolumn{11}{|l|}{ ER+/PR+ (n 155 cases) } \\
\hline \multicolumn{11}{|l|}{ Prudent } \\
\hline No. of cases & 30 & \multicolumn{2}{|c|}{33} & \multicolumn{2}{|c|}{32} & \multicolumn{2}{|c|}{33} & \multicolumn{2}{|c|}{27} & \\
\hline Multivariable adjusted $\dagger$ & 1.00 (Ref.) & $1 \cdot 14$ & $0.69,1.88$ & 1.12 & $0.67,1.86$ & $1 \cdot 15$ & $0.69,1.91$ & 0.96 & $0.56,1.66$ & 0.95 \\
\hline \multicolumn{11}{|l|}{ Westernised } \\
\hline No. of cases & 20 & \multicolumn{2}{|c|}{30} & \multicolumn{2}{|c|}{38} & \multicolumn{2}{|c|}{30} & \multicolumn{2}{|c|}{37} & \\
\hline \multirow{2}{*}{\multicolumn{11}{|c|}{ Traditional }} \\
\hline & & & & & & & & & & \\
\hline No. of cases & 21 & \multicolumn{2}{|c|}{31} & \multicolumn{2}{|c|}{35} & \multicolumn{2}{|c|}{35} & & & \\
\hline Multivariable adjusted & 1.00 (Ref.) & 1.34 & $0.77,2.33$ & 1.36 & $0.79,2 \cdot 34$ & $1 \cdot 24$ & $0.71,2 \cdot 14$ & 1.03 & $0.59,1.81$ & 0.85 \\
\hline ER+/PR- ( $n 58$ cases) & & & & & & & & & & \\
\hline Prudent & & & & & & & & & & \\
\hline No. of cases & 13 & & 9 & & & & & & & \\
\hline Multivariable adjusted & 1.00 (Ref.) & 0.69 & $0.29,1.63$ & 0.77 & $0.33,1.78$ & $1 \cdot 14$ & $0.53,2.45$ & 0.86 & $0.37,1.98$ & 0.84 \\
\hline Westernised & & & & & & & & & & \\
\hline No. of cases & 16 & & 9 & & & & & & & \\
\hline Multivariable adjusted & 1.00 (Ref.) & 0.55 & $0.24,1.25$ & 0.37 & $0.14,0.96$ & 0.82 & $0.38,1.77$ & 0.94 & $0.43,2.04$ & 0.85 \\
\hline Traditional & & & & & & & & & & \\
\hline No. of cases & 12 & & 8 & & & & & & & \\
\hline Multivariable adjusted & 1.00 (Ref.) & 0.58 & $0.24,1.44$ & 0.99 & $0.45,2 \cdot 15$ & 0.78 & $0.35,1.75$ & 0.57 & $0.24,1.36$ & 0.38 \\
\hline ER-/PR- ( $n 85$ cases) & & & & & & & & & & \\
\hline Prudent & & & & & & & & & & \\
\hline No. of cases & 18 & & 8 & & & & & & & \\
\hline Multivariable adjusted & 1.00 (Ref.) & 0.96 & $0.50,1.87$ & 0.83 & $0.41,1.67$ & 0.94 & $0.48,1.86$ & 1.06 & $0.53,2.12$ & 0.92 \\
\hline Westernised & & & & & & & & & & \\
\hline No. of cases & 16 & & 5 & & & & & & & \\
\hline Multivariable adjusted & 1.00 (Ref.) & 0.91 & $0.45,1.84$ & 0.62 & $0.28,1.39$ & 1.46 & $0.75,2.85$ & 1.61 & $0.80,3.22$ & 0.06 \\
\hline Traditional & & & & & & & & & & \\
\hline No. of cases & 10 & & 7 & & & & & & & \\
\hline Multivariable adjusted & 1.00 (Ref.) & 1.45 & $0.66,3.20$ & 1.48 & $0.68,3.22$ & $1 \cdot 37$ & $0.63,2.97$ & $1 \cdot 18$ & $0.53,2.61$ & 0.92 \\
\hline ER/PR unknown ( $n 310$ case & & & & & & & & & & \\
\hline Prudent & & & & & & & & & & \\
\hline No. of cases & 56 & & 6 & & & & & & & \\
\hline Multivariable adjusted & 1.00 (Ref.) & 0.97 & $0.66,1.42$ & 1.21 & $0.84,1.75$ & 1.06 & $0.73,1.56$ & $1 \cdot 13$ & $0.77,1.67$ & 0.44 \\
\hline Westernised & & & & & & & & & & \\
\hline No. of cases & 64 & & 8 & & & & & & & \\
\hline Multivariable adjusted & 1.00 (Ref.) & 1.03 & $0.72,1.46$ & 1.08 & $0.76,1.53$ & 0.66 & $0.44,0.99$ & 0.80 & $0.54,1.19$ & 0.06 \\
\hline Traditional & & & & & & & & & & \\
\hline No. of cases & 61 & & 1 & & & & & & & \\
\hline Multivariable adjusted & 1.00 (Ref.) & 1.09 & $0.77,1.56$ & 0.87 & $0.60,1.27$ & 0.77 & $0.52,1.13$ & $1 \cdot 12$ & $0.77,1.62$ & 0.97 \\
\hline
\end{tabular}

$\mathrm{ER}+$, oestrogen receptor positive; PR+, progesterone receptor positive; Ref., referent values; ER-, oestrogen receptor negative; PR-, progesterone receptor negative.

† Multivariable adjusted: multivariable Cox proportional hazards model was adjusted for age ( $<50,50-54 \cdot 9,55-59 \cdot 9,60-64 \cdot 9,65-69 \cdot 9$, $\geq 70$ years), public health centre area (ten), log-transformed energy intake (continuous), BMI $(<22.5,22.5-24 \cdot 9,25-27.4, \geq 27.5 \mathrm{~kg} / \mathrm{m}$ ), smoking status (never, past, current), leisure-time physical activity $(<1 \mathrm{~d} / \mathrm{month}, 1-3 \mathrm{~d} / \mathrm{month}, \geq 1 \mathrm{~d} / \mathrm{week})$, total physical activity $(<30, \geq 30 \mathrm{metabolic}$ equivalent task-h/d, missing), age at menarche ( $\leq 13,14,15, \geq 16$ years, missing), parity (nulliparous, $1,2-3, \geq 4$ ), age at first birth (nulliparous, $<26, \geq 26$ years, missing), menopause status (premenopause, age at menopause $<51, \geq 51$ years) and use of exogenous female 
pattern on breast cancer likely reflect overall dietary behaviours, which may in turn explain a mixture of social, cultural, environmental, health, economic and lifestyle factors $^{(44)}$. In the present study, we could not obtain consistent findings for any associations of westernised dietary pattern with risk of breast cancer among premenopausal women. The possible differential effect by menopausal status could be due to the influence of genetic factors and early-life events, which are stronger for premenopausal breast cancer ${ }^{(45,46)}$. For example, a prospective study performed on breast cancer in Italy reported that a higher ratio of 2-hydroxyestrone (lower oestrogenic activity):16 $\alpha$-hydroxyestrone (biologically strong oestrogens) was associated with reduced risk of breast cancer among premenopausal women, but not in postmenopausal women ${ }^{(47)}$. Furthermore, age-related changes in local tissue metabolism of sex steroids such as oestrogen, testosterone and progesterone $^{(48)}$ may be partially explained by some differences between dietary factor and breast cancer risk in premenopausal and postmenopausal women. Another possible reason is that the lack of statistical significance in premenopausal women might be due to chance, given the relatively small number of cases of breast cancer in our premenopausal subjects. In our study, the westernised dietary pattern had a strong positive effect on ER+/PR+ tumours. Although a few studies have assessed dietary patterns and nutrients with regard to ER/PR subtype, two studies reported a significant inverse association for the prudent dietary pattern and ER- breast cancer in black women ${ }^{(27)}$ and in postmenopausal women in the Nurses' Health Study ${ }^{(17)}$. Regarding components of the westernised diet, alcohol intake $^{(49)}$ and excess dietary fat ${ }^{(50,51)}$ were more strongly associated with ER+ than ER- tumours, although other studies found no evidence of an association with dietary fat by ER/PR status $^{(52,53)}$. Thus, future aetiological studies of breast cancer should stratify analyses by tumour receptor type.

The major strengths of this study include its large sample size and population-based prospective design, in which information was collected before the subsequent diagnosis of breast cancer, thereby avoiding the exposure recall bias inherent to casecontrol studies. Our subjects were recruited from the general population, the sample was large, the response rate to the questionnaire was more than $80 \%$ and loss to follow-up was a negligible $0.4 \%{ }^{(19)}$. In addition, the cancer registry of the study population was of sufficient quality to reduce the possibility of misclassification of outcomes. To examine the association between breast cancer risk and dietary factors, we used the dietary pattern method to identify the overall dietary habits of our subjects. This approach is particularly useful when planning dietary preventive strategies or carrying our nutritional education, because it considers the overall diet, and therefore encompasses complex relations, potential interactions and synergetic effects among nutrients, food and other food components.

Several limitations to the present study warrant mention. First, principal component analyses require several subjective decisions in determining the number of factors to be retained, the method of rotation of the initial factors and the labelling of dietary patterns ${ }^{(18,54)}$. Although the dietary patterns in this study cannot be compared directly with those of other studies because of differences in the process, they are similar to those reported previously among Japanese ${ }^{(55,56)}$. Moreover, we confirmed that the validity and reproducibility of the three dietary patterns derived from subsamples were reasonable ${ }^{(24)}$. Second, we assessed the usual dietary intake only at one time point, and long-term dietary changes may not be accurately reflected during the follow-up period. Third, although we examined and adjusted for several potential confounders in the statistical model, the possible effects of confounding by unmeasured variables and residual confounding cannot be totally discarded.

In summary, we found that a westernised dietary pattern with high intake of meat, processed meat, bread, dairy products, coffee, soft drinks, tea, sauces and alcohol was associated with an increase in the risk of breast cancer in a large sample of Japanese women. In particular, the increased risk associated with this dietary pattern was more pronounced among those women with extremely high intake (top of $4 \%$ ) of a western diet, those who were postmenopausal and those with ER+/PR+ tumours. This increased risk with the western dietary pattern in this cohort study may be due to the intake of specific combinations of food or food components, the diet pattern as a whole or other unconsidered characteristics of individuals who consume this diet. Therefore, these findings may indicate a potential avenue for public health intervention.

\section{Acknowledgements}

This study was supported by the National Cancer Center Research and Development Fund (23-A-31(toku) and 26-A-2) (since 2011) and a Grant-in-Aid for Cancer Research from the Ministry of Health, Labour and Welfare of Japan (from 1989 to 2010). S. Shin was supported by the basic science research programme through the National Research Foundation of Korea funded by the Ministry of Education, Science and Technology (2014R1A6A3A03056928). M. Inoue is the beneficiary of a financial contribution from the AXA Research Fund as chair holder of the AXA Department of Health and Human Security, Graduate School of Medicine, The University of Tokyo. The AXA Research Fund had no role in the design, data collection, analysis, interpretation or drafting of the manuscript, or in the decision to submit the manuscript for publication.

The author responsibilities were as follows $-\mathrm{S}$. Shin analysed the data and drafted the manuscript; M. Inoue, S. T., E. S., N. S., T. S., T. Y., M. Iwasaki, S. Sasazuki, J. I., R. T. and A. N. reviewed and edited the manuscript and contributed to the discussion; $\mathrm{M}$. Inoue and S. T. conducted, designed and supervised the study; and all the authors read and approved the final version of the manuscript.

None of the authors reported any conflicts of interest related to the study.

\section{References}

1. Parkin DM, Bray F, Ferlay J, et al. (2005) Global cancer statistics, 2002. CA Cancer J Clin 55, 74-108.

2. Ferlay J, Soerjomataram I, Dikshit R, et al. (2015) Cancer incidence and mortality worldwide: sources, methods and major patterns in GLOBOCAN 2012. Int J Cancer 136, E359-E386. 
3. Matsuda T, Marugame T, Kamo K, et al. (2009) Cancer incidence and incidence rates in Japan in 2003: based on data from 13 population-based cancer registries in the Monitoring of Cancer Incidence in Japan (MCIJ) Project. Jpn J Clin Oncol 39, 850-858.

4. Gandini S, Merzenich H, Robertson C, et al. (2000) Meta-analysis of studies on breast cancer risk and diet: the role of fruit and vegetable consumption and the intake of associated micronutrients. Eur J Cancer 36, 636-646.

5. Smith-Warner SA, Spiegelman D, Yaun SS, et al. (2001) Intake of fruits and vegetables and risk of breast cancer: a pooled analysis of cohort studies. JAMA 285, 769-776.

6. Michels KB, Mohllajee AP, Roset-Bahmanyar E, et al. (2007) Diet and breast cancer: a review of the prospective observational studies. Cancer 109, 2712-2749.

7. Edefonti V, Randi G, La Vecchia C, et al. (2009) Dietary patterns and breast cancer: a review with focus on methodological issues. Nutr Rev 67, 297-314.

8. Velie EM, Schairer C, Flood A, et al. (2005) Empirically derived dietary patterns and risk of postmenopausal breast cancer in a large prospective cohort study. Am J Clin Nutr $\mathbf{8 2}$, 1308-1319.

9. Adebamowo CA, Hu FB, Cho E, et al. (2005) Dietary patterns and the risk of breast cancer. Ann Epidemiol 15, 789-795.

10. Hirose K, Matsuo K, Iwata H, et al. (2007) Dietary patterns and the risk of breast cancer in Japanese women. Cancer Sci $\mathbf{9 8}$, 1431-1438.

11. Sieri S, Krogh V, Pala V, et al. (2004) Dietary patterns and risk of breast cancer in the ORDET cohort. Cancer Epidemiol Biomarkers Prev 13, 567-572.

12. Sant M, Allemani C, Sieri S, et al. (2007) Salad vegetables dietary pattern protects against HER-2-positive breast cancer: a prospective Italian study. Int J Cancer 121, 911-914.

13. Wu AH, Yu MC, Tseng CC, et al. (2009) Dietary patterns and breast cancer risk in Asian American women. Am J Clin Nutr 89, $1145-1154$

14. Cui X, Dai Q, Tseng M, et al. (2007) Dietary patterns and breast cancer risk in the Shanghai breast cancer study. Cancer Epidemiol Biomarkers Prev 16, 1443-1448.

15. De Stefani E, Deneo-Pellegrini H, Boffetta P, et al. (2009) Dietary patterns and risk of cancer: a factor analysis in Uruguay. Int J Cancer 124, 1391-1397.

16. Engeset D, Dyachenko A, Ciampi A, et al. (2009) Dietary patterns and risk of cancer of various sites in the Norwegian European Prospective Investigation into Cancer and Nutrition cohort: the Norwegian Women and Cancer study. Eur $J$ Cancer Prev 18, 69-75.

17. Fung TT, Hu FB, Holmes MD, et al. (2005) Dietary patterns and the risk of postmenopausal breast cancer. Int J Cancer 116, 116-121.

18. Hu FB (2002) Dietary pattern analysis: a new direction in nutritional epidemiology. Curr Opin Lipidol 13, 3-9.

19. Tsugane S \& Sawada N (2014) The JPHC study: design and some findings on the typical Japanese diet. Jpn J Clin Oncol 44, 777-782.

20. Sasaki S, Kobayashi M, Ishihara J, et al. (2003) Selfadministered food frequency questionnaire used in the 5-year follow-up survey of the JPHC study: questionnaire structure, computation algorithms, and area-based mean intake. J Epidemiol 13, S13-S22.

21. Ishihara J, Sobue T, Yamamoto S, et al. (2003) Validity and reproducibility of a self-administered food frequency questionnaire in the JPHC Study Cohort II: study design, participant profile and results in comparison with Cohort I. J Epidemiol 13, S134-S168.
22. Sasaki S, Kobayashi M \& Tsugane S (2003) Validity of a self-administered food frequency questionnaire used in the 5-year follow-up survey of the JPHC Study Cohort I: comparison with dietary records for food groups. J Epidemiol 13, S57-S63.

23. Sasaki S, Ishihara J \& Tsugane S (2003) Reproducibility of a self-administered food frequency questionnaire used in the 5-year follow-up survey of the JPHC Study Cohort I to assess food and nutrient intake. J Epidemiol 13, S115-S124.

24. Nanri A, Shimazu T, Ishihara J, et al. (2012) Reproducibility and validity of dietary patterns assessed by a food frequency questionnaire used in the 5-year follow-up survey of the Japan Public Health Center-Based Prospective Study. J Epidemiol 22, 205-215.

25. Wada K, Nagata C, Tamakoshi A, et al. (2014) Body mass index and breast cancer risk in Japan: a pooled analysis of eight population-based cohort studies. Ann Oncol 25, 519-524.

26. Baglietto L, Krishnan K, Severi G, et al. (2011) Dietary patterns and risk of breast cancer. Br J Cancer 104, 524-531.

27. Agurs-Collins T, Rosenberg L, Makambi K, et al. (2009) Dietary patterns and breast cancer risk in women participating in the Black Women's Health Study. Am J Clin Nutr 90, 621-628.

28. Mannisto S, Dixon LB, Balder HF, et al. (2005) Dietary patterns and breast cancer risk: results from three cohort studies in the DIETSCAN project. Cancer Causes Control 16, 725-733.

29. Terry P, Suzuki R, Hu FB, et al. (2001) A prospective study of major dietary patterns and the risk of breast cancer. Cancer Epidemiol Biomarkers Prev 10, 1281-1285.

30. Cottet V, Touvier M, Fournier A, et al. (2009) Postmenopausal breast cancer risk and dietary patterns in the E3N-EPIC prospective cohort study. Am J Epidemiol 170, 1257-1267.

31. Butler LM, Wu AH, Wang R, et al. (2010) A vegetable-fruit-soy dietary pattern protects against breast cancer among postmenopausal Singapore Chinese women. Am J Clin Nutr 91, 1013-1019.

32. Zhang CX, Ho SC, Fu JH, et al. (2011) Dietary patterns and breast cancer risk among Chinese women. Cancer Causes Control 22, 115-124.

33. Guo JY, Wei W \& Zhan LX (2015) Red and processed meat intake and risk of breast cancer: a meta-analysis of prospective studies. Breast Cancer Res Treat 151, 191-198.

34. Knize MG, Salmon CP, Pais P, et al. (1999) Food heating and the formation of heterocyclic aromatic amine and polycyclic aromatic hydrocarbon mutagens/carcinogens. Adv Exp Med Biol 459, 179-193.

35. Kazerouni N, Sinha R, Hsu CH, et al. (2002) Analysis of 200 food items for benzo(a)pyrene and estimation of its intake in an epidemiologic study. Food Chem Toxicol 39, 423-436.

36. Bonner MR, Han DW, Nie L, et al. (2005) Breast cancer risk and exposure in early life to polycyclic aromatic hydrocarbons using total suspended particulates as a proxy measure. Cancer Epidemiol Biomarkers Prev 14, 53-60.

37. Zheng W \& Lee SA (2009) Well-done meat intake, heterocyclic amine exposure, and cancer risk. Nutr Cancer 61, 437-446.

38. World Cancer Research Fund/American Institute for Cancer Research (2007) Food, Nutrition, Physical Activity and the Prevention of Cancer: A Global Perspective. Washington, DC: AICR.

39. Smith-Warner SA, Spiegelman D, Adami HO, et al. (2001) Types of dietary fat and breast cancer: a pooled analysis of cohort studies. Int J Cancer $\mathbf{9 2}, 767-774$

40. Tjonneland A, Christensen J, Olsen A, et al. (2007) Alcohol intake and breast cancer risk: the European Prospective Investigation into Cancer and Nutrition (EPIC). Cancer Cause Control 18, 361-373. 
41. Zhang SM, Willett WC, Selhub J, et al. (2003) Plasma folate, vitamin $\mathrm{B}_{6}$, vitamin $\mathrm{B}_{12}$, homocysteine, and risk of breast cancer. $J$ Natl Cancer Inst 95, 373-380.

42. Lew JQ, Freedman ND, Leitzmann MF, et al. (2009) Alcohol and risk of breast cancer by histologic type and hormone receptor status in postmenopausal women: the NIH-AARP Diet and Health Study. Am J Epidemiol 170, 308-317.

43. Bradshaw PT, Sagiv SK, Kabat GC, et al. (2009) Consumption of sweet foods and breast cancer risk: a case-control study of women on Long Island, New York. Cancer Causes Control 20, 1509-1515.

44. Reedy J, Wirfalt E, Flood A, et al. (2010) Comparing 3 dietary pattern methods-cluster analysis, factor analysis, and index analysis-with colorectal cancer risk. Am J Epidemiol 171, 479-487.

45. Lagiou P, Hsieh CC, Trichopoulos D, et al. (2008) Neonatal growth and breast cancer risk in adulthood. Br J Cancer 99 , $1544-1548$

46. Loman N, Johannsson O, Kristoffersson U, et al. (2001) Family history of breast and ovarian cancers and BRCA1 and BRCA2 mutations in a population-based series of early-onset breast cancer. J Natl Cancer Inst 93, 1215-1223.

47. Muti P, Bradlow HL, Micheli A, et al. (2000) Estrogen metabolism and risk of breast cancer: a prospective study of the 2:16alpha-hydroxyestrone ratio in premenopausal and postmenopausal women. Epidemiology 11, 635-640.

48. Hankinson SE \& Eliassen AH (2007) Endogenous estrogen, testosterone and progesterone levels in relation to breast cancer risk. J Steroid Biochem Mol Biol 106, 24-30.

49. Suzuki R, Ye WM, Rylander-Rudqvist T, et al. (2005) Alcohol and postmenopausal breast cancer risk defined by estrogen and progesterone receptor status: a prospective cohort study. J Natl Cancer Inst 97, 1601-1608.

50. Kushi LH, Potter JD, Bostick RM, et al. (1995) Dietary-fat and risk of breast-cancer according to hormone-receptor status. Cancer Epidemiol Biomarkers Prev 4, 11-19.

51. Sieri S, Chiodini P, Agnoli C, et al. (2014) Dietary fat intake and development of specific breast cancer subtypes. $J$ Natl Cancer Inst 106, dju068.

52. Park SY, Kolonel LN, Henderson BE, et al. (2012) Dietary fat and breast cancer in postmenopausal women according to ethnicity and hormone receptor status: the Multiethnic Cohort Study. Cancer Prev Res 5, 216-228.

53. Kim EHJ, Willett WC, Colditz GA, et al. (2006) Dietary fat and risk of postmenopausal breast cancer in a 20-year follow-up. Am J Epidemiol 164, 990-997.

54. Martinez ME, Marshall JR \& Sechrest L (1998) Invited commentary: factor analysis and the search for objectivity. Am J Epidemiol 148, 17-19.

55. Kashino I, Nanri A, Kurotani K, et al. (2015) Association of dietary patterns with serum adipokines among Japanese: a cross-sectional study. Nutr J 14, 58 .

56. Kurotani K, Kochi T, Nanri A, et al. (2015) Dietary patterns and sleep symptoms in Japanese workers: the Furukawa Nutrition and Health Study. Sleep Med 16, 298-304.

\section{Appendix}

The members of the Japan Public Health Center-based Prospective Study (principal investigator: S. Tsugane) Group are as follows: S. Tsugane, N. Sawada, M. Iwasaki, S. Sasazuki,
T. Yamaji, T. Shimazu and T. Hanaoka, National Cancer Center, Tokyo; J. Ogata, S. Baba, T. Manami, A. Okayama, and Y. Kokubo, National Cerebral and Cardiovascular Center, Osaka; K. Miyakawa, F. Saito, A. Koizumi, Y. Sano, I. Hashimoto, T. Ikuta, Y. Tanaba, H. Sato, Y. Roppongi, and T. Takashima, Iwate Prefectural Ninohe Public Health Center, Iwate; Y. Miyajima, N. Suzuki, S. Nagasawa, Y. Furusugi, N. Nagai, Y. Ito, S. Komatsu and T. Minamizono, Akita Prefectural Yokote Public Health Center, Akita; H. Sanada, Y. Hatayama, F. Kobayashi, H. Uchino, Y. Shirai, T. Kondo, R. Sasaki, Y. Watanabe, Y. Miyagawa, Y. Kobayashi, M. Machida, K. Kobayashi and M. Tsukada, Nagano Prefectural Saku Public Health Center, Nagano; Y. Kishimoto, E. Takara, T. Fukuyama, M. Kinjo, M. Irei, and H. Sakiyama, Okinawa Prefectural Chubu Public Health Center, Okinawa; K. Imoto, H. Yazawa, T. Seo, A. Seiko, F. Ito, F. Shoji and R. Saito, Katsushika Public Health Center, Tokyo; A. Murata, K. Minato, K. Motegi, T. Fujieda and S. Yamato, Ibaraki Prefectural Mito Public Health Center, Ibaraki; K. Matsui, T. Abe, M. Katagiri, M. Suzuki, K. and Matsui, Niigata Prefectural Kashiwazaki and Nagaoka Public Health Center, Niigata; M. Doi, A. Terao, Y. Ishikawa, and T. Tagami, Kochi Prefectural Chuo-higashi Public Health Center, Kochi; H. Sueta, H. Doi, M. Urata, N. Okamoto, and F. Ide and H. Goto, Nagasaki Prefectural Kamigoto Public Health Center, Nagasaki; H. Sakiyama, N. Onga, H. Takaesu, M. Uehara, T. Nakasone and M. Yamakawa, Okinawa Prefectural Miyako Public Health Center, Okinawa; F. Horii, I. Asano, H. Yamaguchi, K. Aoki, S. Maruyama, M. Ichii, and M. Takano, Osaka Prefectural Suita Public Health Center, Osaka; Y. Tsubono, Tohoku University, Miyagi; K. Suzuki, Research Institute for Brain and Blood Vessels Akita, Akita; Y. Honda, K. Yamagishi, S. Sakurai and N. Tsuchiya, University of Tsukuba, Ibaraki; M. Kabuto, National Institute for Environmental Studies, Ibaraki; M. Yamaguchi, Y. Matsumura, S. Sasaki, and S. Watanabe, National Institute of Health and Nutrition, Tokyo; M. Akabane, Tokyo University of Agriculture, Tokyo; T. Kadowaki and M. Inoue, The University of Tokyo, Tokyo; M. Noda and T. Mizoue, National Center for Global Health and Medicine, Tokyo; Y. Kawaguchi, Tokyo Medical and Dental University, Tokyo; Y. Takashima and Y. Yoshida, Kyorin University, Tokyo; K. Nakamura and R. Takachi, Niigata University, Niigata; J. Ishihara, Sagami Women's University, Kanagawa; S. Matsushima and S. Natsukawa, Saku General Hospital, Nagano; H. Shimizu, Sakihae Institute, Gifu; H. Sugimura, Hamamatsu University School of Medicine, Shizuoka; S. Tominaga, Aichi Cancer Center, Aichi; N. Hamajima, Nagoya University, Aichi; H. Iso and T. Sobue, Osaka University, Osaka; M. Iida, W. Ajiki, and A. Ioka, Osaka Medical Center for Cancer and Cardiovascular Disease, Osaka; S. Sato, Chiba Prefectural Institute of Public Health, Chiba; E. Maruyama, Kobe University, Hyogo; M. Konishi, K. Okada, and I. Saito, Ehime University, Ehime; N. Yasuda, Kochi University, Kochi; S. Kono, Kyushu University, Fukuoka; S. Akiba, Kagoshima University, Kagoshima. 